\title{
Information Sharing and Optimum Financing Mode
}

\author{
Gabriella Chiesa \\ gchiesa@economia.unibo.it \\ Department of Economics \\ University of Bologna*
}

\begin{abstract}
What drives the choice of financing/organization mode of R\&D? What the implications of property rights protection, and firm organizational form? Within a setting where an established firm (incumbent) and a new venture engage in $R \& D$ and compete in the product market, we analyze the incentives to cooperate at the $R \& D$ stage, the incentive schemes offered to agents, and the optimum financing mode of the new venture. We show that: $i$ ) if an equilibrium is one where firms cooperate, then it is one where financing is provided by the incumbent; ii) incentive schemes are costlier under cooperation. Cooperation is more likely in organizations where agency problems are less severe, e.g. family firms, and the riskier the $R \& D$ process; iii) if the $R \& D$ output is patentable, cooperation is implemented ex-post via licensing and the optimum financing mode has financing provided by a pure financial institution.
\end{abstract}

Key Words: R\&D; information sharing; financing; incentives.

JEL classification: D23; D80; G32.

${ }^{*}$ Piazza Scaravilli 2, 40126 Bologna, Italy 


\section{Introduction}

R\&D activity is performed according to different organizational forms and financed according to different modes. In the Anglo-Saxon system, we observe a flourishing Venture Capital activity carried out by pure financing institutions. At the same time we observe strategic alliances between companies during the different stages of the $R \& D$ process as well as venture capital activity carried out by non-financing firms (corporate venture capital). In the so called industrial districts, start-ups are nourished by the existing (established) firms with the established firm playing the role of "venture capitalist". What drives different financing/organization modes? What the implications of property rights protection, i.e. innovation patentability and subsequent licensing contract feasibility? And what the implications of firm organizational form, like family firms versus more articulated structures with well defined "division of tasks" possibly prone to agency problems?

This paper attempts to tackle these questions. We examine a model where an established firm (incumbent) and a new venture engage in $R \& D$ and subsequently compete in the product market. We analyze the incentives to cooperate at the $R \& D$ stage (i.e. share the $R \& D$ results), the incentive schemes offered to agents, and the optimum financing mode of the new venture. We show that: i) if an equilibrium is one where firms cooperate, then it is one where financing is provided by the incumbent; ii) agents' incentive schemes are costlier under cooperation. Cooperation is attained if the gains achievable in a first-best world are not undermined by agency costs, and this is more likely in organizational structures where agency problems are less severe, like for example family firms, and the riskier is the R\&D process; iii) If the $R \& D$ output is patentable, then cooperation is implemented ex-post via licensing and an optimum financing mode has financing provided by a pure financial institution.

The leading explanation offered by corporations with regard to their venture capital activity, is that start-up financing allows to achieve synergies with the corporation's core business. Indeed, it is very often the case that both corporations and the new venture engage in $R \& D$ activity with the ultimate goal of developing products that will be traded in the same market. The value attained by these activities will be interdependent and differ according to whether the parties engage or abstain from cooperation, 
that is according to whether the synergies between their activities are exploited. We model cooperation as sharing the $R \& D$ results (information exchange). Even though the two firms may compete fiercely in the final product market, cooperation may still be beneficial in that it enhances the likelihood that a marketable product will be developed. However, under cooperation, a double moral hazard problem arises. Agents involved in the R\&D activity may wish to free ride on the rival's activity, and this implies that agents' incentive schemes are costlier, because part of the surplus generated from cooperation accrues to agents. The Principal may not find it optimal to offer such costly incentive schemes, since it suffers the cost and shares the benefits with the counterpart via information exchange. Holding a stake in the counterpart's venture allows the incumbent to internalize part of these benefits, the greater the stake the greater the extent to which the parties cooperate in maximizing the likelihood that the overall $R \& D$ activity will indeed succeed. Maximizing the gains from cooperation subject to participation constraints being satisfied, i.e. subject to the parties earning an expected payoff that does not fall below what they would obtain by performing the ventures independently, then requires full financing being provided by the incumbent. We then have the result that if cooperation is optimal, i.e. if the benefits attainable in a First-Best world are not undermined by the agency costs that cooperation carries, then the investor will not be a pure financial institution but rather the company whose business is prone to synergies with the start-up. By contrast, if cooperation is not optimal, then financing will be provided by a pure financial institution so as to minimize information leakages to rivals. Whether cooperation is desirable, crucially depends on whether $\mathrm{R} \& \mathrm{D}$ results are patentable. If they are patentable, then licensing will allow the parties to share the $R \& D$ results ex post, since the licensor (the innovator) can give its rival (licensee) the right to use the innovation in exchange for a fee. Licensing then allows the two parties to use the $R \& D$ result in the product-development stage exactly as with information exchange, without incurring in the free riding problems that information exchange gives raise. Consequently, if the R\&D output is patentable, then the total surplus generated under no-information exchange cum efficient licensing exceeds that attained under information exchange, and the optimum financing mode has financing provided by a pure financial institution. 
These results may help explain different patterns of R\&D financing across sectors and countries. In sectors where innovations are primarily incremental in the sense that cannot meet patentability requirements, or are such that "inventing around" is likely so that the optimal strategy is not to publicly disclose the innovation, as would be required by patenting it, we will not find much of venture capital financing of the Anglo-Saxon type, but rather cooperation among firms cemented by finance provision and equity participations. The more so the lower agency costs, like for example in family firms where principals and agents coexist in the same entity. Analogous conclusions hold for countries where patent protection is limited.

The paper is linked to the literature on information sharing, and on venture capital. D'Aspremont et al. (2000), Bhattacharya et al. (1992), Katz \& Shapiro (1987) study the incentive for knowledge transfer in the context of licensing. Severinov (2001) endogenizes R\&D spillover across firms and characterizes the contracts offered to employees that implement the desired information flows between them. Bhattacharya and Chiesa (1995) contrasts equilibria with bilateral bank-borrower ties, in which knowledge is not revealed to product market competitors, with equilibria under multilateral financing in which such knowledge may be shared among competing firms, and studies the ex-ante optimal regime (bilateral/multilateral) when the firms engaged in R\&D need outside financing. This paper focuses on the incentive-compatible provision of incentives for $R \& D$ that result from the choice of the information regime and that of the financing mode, when $R \& D$ financing can be provided internally (i.e. by the incumbent, the established firm) and information flows cannot be controlled by third parties (in contrast to Bhattacharya Chiesa, 1995). Hellmann (2002) addresses the topic of strategic venture investments by analyzing the competition for start-up financing between a pure financial investor and a strategic investor, where the latter is an established firm that owns an asset whose value is affected by the new venture. This paper complements Hellmann (2002) in that the performance of both ventures, the start up and the established firm, are interdependent and endogenously determined by the financing mode.

The rest of the paper is organized as follows. Section 2 presents the basic model. Section 3 derives the equilibrium financial arrangement for the binary actions' model. Section 4 extends the analysis to a continuum of actions. Section 5 allows for patentability and analyzes licensing. Section 6 
concludes.

\section{The Model}

\subsection{The Setting}

Consider a risk-neutral world with no discounting. An entrepreneur $(E)$ wants to start a new venture that requires an amount $L$, but has no wealth. He can approach a competitive pool of independent venture capitalists $(V C)$ and/or a strategic investor. This is an incumbent $(I)$ that differs from $V C$ in that he owns a venture whose performance interacts with that of the entrant: the entrant's venture performance depends on the incumbent's venture performance and viceversa. Both ventures consist of two stages, a research stage and a subsequent development stage that, if successful, delivers a new marketable product. The research result, $r_{i}, i=E, I$, can be either unsuccess, $\emptyset$, or success, in which case the research activity delivers an output $(k)$, this output is a necessary input for the subsequent (development) stage. The development stage, which takes place if and only if the firm has the research output $k$, succeeds with probability $P$ no matter the firm's identity (whether the firm is that of the entrant or the one of the incumbent). If both firms are successful at the development stage, then Bertand competition drives profits to zero. If one of the two firms is the only one that is successful at the development stage, then its payoff is $V$, and that of its competitor is zero. This is summarized in Table 1 , where $E\left(\widetilde{V}_{E} \mid ..\right), E\left(\widetilde{V}_{I} \mid ..\right)$ denote the expected value of the venture, conditional upon the availability/unavailability of the research output $(k / \emptyset)$, of the entrant and of the incumbent, respectively; $V^{c} \equiv P(1-P) V$, is the expected value of the venture conditionally upon both the entrant and the incumbent having the research output $k$, i.e. conditionally upon both the entrant and the incumbent entering the development stage; $\bar{V} \equiv P V$ is the expected value of the venture that has the research output $k$ (enters the development stage) conditionally upon its rival not having the research output, i.e. conditionally upon its rival not entering the development stage.

Table 1 About Here 
The incumbent is an established firm where the entrepreneur (Principal) delegates the research activity to an agent (the research department). The agent is risk neutral but limited liable, his reservation utility is zero. The agent's choice of action determines the probability of success of the research stage. The research result is $k$ with probability $a$ :

$$
a \in\{0, p\}
$$

where

$$
0<p<1
$$

The agent's cost of action, $c(a)$, is :

$$
\begin{aligned}
& c(a=p)=c \\
& c(a=0)=0
\end{aligned}
$$

where $c$ is a strictly positive non-pecuniary cost. We can think of $a=p$ as the agent exercising effort.

By contrast, the entrant is directly involved in the research process, this succeeds with probability $0<q<1$ provided that the entrant invests the cash-outlay $L$.

Suppose that the entrant can enter the development stage if and only if his research stage is successful, and similarly for the incumbent, and that the latter elicits the agent's effort $(a=p)$. Then the expected value of the entrant's venture is

$$
q\left[p V^{c}+(1-p) \bar{V}\right],
$$

and that of the incumbent's venture is:

$$
p\left[q V^{c}+(1-q) \bar{V}\right] .
$$

We assume that:

$$
\begin{gathered}
q\left[p V^{c}+(1-p) \bar{V}\right]-L>0 \\
p\left[q V^{c}+(1-q) \bar{V}\right]-c>0,
\end{gathered}
$$

i.e. the net present value of the entrant's venture, conditionally upon the incumbent's eliciting the agent's effort, is positive (by (1)); and the net 
present value of the incumbent's venture, conditionally upon effort elicitation at the cost $c$, is positive (by (2)).

In principle, even if the incumbent's research is unsuccessful he can still enter the development stage if the entrant's research succeeds and this (successful) result is disclosed to him, and similarly for the entrant. We shall assume that the research result is non-patentable (but see Section 5) and hence a spot market for the research result is unfeasible. However, we shall allow for the feasibility of information exchange (ex-ante) agreements. The potential benefit of the incumbent of agreeing ex-ante to information exchange arises from the possible occurrence of the state in which his research fails and that of the entrant succeeds. Then the incumbent's expected payoff under no-information exchange is nil, whereas given information exchange is $V^{c} \equiv P(1-P) V$. The potential benefit of the entrant from ex-ante information-exchange agreement shares the same roots, but it is there provided that the incumbent finds it incentive compatible to elicit the agent's effort (in which case the incumbent's research activity succeeds with probability $p$ ). If this were not the case, i.e. if the incumbent would save on costly elicitation of effort, then his research would fail for sure. The informationexchange agreement would de facto be one where the entrant unilaterally transfers his research result to the incumbent. The following assumption rules out that this can be part of an equilibrium:

$$
\begin{gathered}
\left\{q\left[p V^{c}+(1-p) \bar{V}\right]-L\right\}+\left\{p\left[q V^{c}+(1-q) \bar{V}\right]-c\right\}>S S_{a=0}^{E} \\
S S_{a=0}^{E} \equiv\left\{q V^{c}-L\right\}+q V^{c}
\end{gathered}
$$

The expression in the left-hand side of (3) is the expected social surplus, i.e. the sum of the net-present value of the entrant's and incumbent's ventures, or equivalently the sum of the entrant's and incumbent's expected payoffs, which is attained under no-information exchange and effort elicitation by the incumbent at the cost $c ; S S_{a=0}^{E}$ is the expected social surplus that would be attained under information exchange and no effort elicitation by the incumbent, i.e. $a=0$ - the incumbent's research fails for sure. Suppose that under no-information exchange the incumbent elicits the agent's effort and that effort elicitation costs $c$, then (3) implies that no-information exchange Pareto dominates information-exchange agreements that do not lead 
to effort elicitation. We assume that (3) holds, by so doing we rule out the trivial outcome that information exchange is always part of an equilibrium.

Inequality (3) can be written as:

$$
\begin{gathered}
c<\bar{c} \\
\bar{c} \equiv P V[p-q+2 q(1-p) P],
\end{gathered}
$$

that is (3) is an upper-bound constraint on $c$, the agent's cost of exercising effort.

In a first best world where everything is observable and contractible, the incumbent can pre-commit contractually to elicit the agent's effort and the agent can commit to exert effort in exchange for compensation $c$. We prove below that in a first best world: i) the parties would agree to information exchange when the development stage is sufficiently risky, that is when $P$, the probability according to which the development succeeds, satisfies $P \leq \frac{1}{2}$; ii) the choice of the source of financing, whether the entrant raises financing from the $\mathrm{VC}$ or the incumbent, is disjoint from the choice of information exchange.

\subsection{The First Best Outcome}

Consider a first-best world where everything is observable and contractible: the agent can commit to exert effort in exchange for compensation $c$, and the incumbent can pre-commit contractually to elicit the agent's effort.

Consider an information exchange agreement with precommitment of the incumbent to elicit the agent's effort. Given this agreement, both the entrant and the incumbent will enter the development stage whenever at least one of the two research activities succeeds, this occurs with probability $[1-(1-p)(1-q)]$. Moreover, in a first-best world the agent's effort is elicited at the cost $c$ (because agent's actions are contractible). The net present value of the incumbent's venture is then $\pi_{I}^{E *}$ :

$$
\pi_{I}^{E *}=[1-(1-p)(1-q)] V^{c}-c
$$

and that of the entrant is $\pi_{E}^{E *}$ :

$$
\pi_{E}^{E *}=[1-(1-p)(1-q)] V^{c}-L
$$


Under a regime no-information exchange, the net present value of the incumbent's venture is $\pi_{I}^{N E *}$ :

$$
\pi_{I}^{N E *}=p\left[q V^{c}+(1-q) \bar{V}\right]-c
$$

and that of the entrant is $\pi_{E}^{N E *}$ :

$$
\pi_{E}^{N E *}=q\left[p V^{c}+(1-p) \bar{V}\right]-L .
$$

The parties will agree to information-exchange (cum agent's effort elicitation) if and only if:

$$
\begin{aligned}
& \pi_{I}^{E *} \geq \pi_{I}^{N E *} \\
& \pi_{E}^{E *} \geq \pi_{E}^{N E *} .
\end{aligned}
$$

That is iff:

$$
S S^{E^{*}} \geq S S^{N E *}
$$

where:

$$
S S^{E^{*}} \equiv \pi_{I}^{E *}+\pi_{E}^{E *}=[1-(1-p)(1-q)] 2 V^{c}-(c+L)
$$

is the expected social surplus attained under information exchange and effort elicitation at the cost $c$; and

$$
S S^{N E *} \equiv \pi_{I}^{N E *}+\pi_{E}^{N E *}=\left\{q\left[p V^{c}+(1-p) \bar{V}\right]-L\right\}+\left\{p\left[q V^{c}+(1-q) \bar{V}\right]-c\right\}
$$

is the expected social surplus attained under no-information exchange.

Inequality (4) holds if and only if

$$
[q(1-p)+p(1-q)]\left[2 V^{c}-\bar{V}\right] \geq 0
$$

that is iff $2 V^{c} \geq \bar{V}$, which is true iff:

$$
2 P(1-P) V \geq P V
$$

where $P$ is the probability according to which the development stage is successful, $V$ is the firm's revenue conditionally upon being the only successful product developer. 
Lemma 1 In a First-Best world the incumbent elicits the agent's effort and this costs $c$, the entrant undertakes the project, and when $P \leq \frac{1}{2}$, the parties agree to information-exchange .

Proof. Directly from (1) - (2) and (4.b) .

In the first-best world, the incumbent can precommit contractually to elicit the agent's effort. Information exchange agreements that lead to effort elicitation are then feasible independently of the entrant's source of financing. That is, in the first-best world, the choice of the source of financing, whether the entrant raises financing from the $\mathrm{VC}$ or the incumbent, is disjoint from the choice of information regime.

\subsection{Feasible Contracts}

We depart from the first-best world. The set of contracts that can be enforced is restricted because: i) the agent's choice of action is unobservable; ii) the incumbent cannot precommit to elicit the agent's effort. However, projects' terminal payoff realizations (either $V$ or 0 ) are observable and verifiable, that is incentive schemes for the agent can be conditioned on projects' terminal payoffs. Moreover, research results are non-patentable (see Section 5 for the implications of patentability).

Figure 1 describes the sequence of choices and events.

Figure 1 About Here

We shall see that, in contrast with the first-best world, the possibility of information exchange affects the choice of the financing mode.

\section{Equilibrium Financing Mode}

This section derives the equilibrium financing mode and more generally the solution attained in the second-best world of non-contractibility of actions and non patentability of research outcomes. As it will become clear soon, the relevant (undominated) financing modes are Incumbent's financing cum information exchange and VC financing with no interaction between the incumbent and the entrant (no-information exchange). We shall refer to the latter simply as VC financing. 


\subsection{VC Financing}

Consider VC financing, the net present value of the entrant's venture, conditional upon the incumbent undertaking the project (i.e. eliciting the agent's effort), is $\pi_{E}^{V C}$ :

$$
\pi_{E}^{V C}=q\left[p V^{c}-(1-p) \bar{V}\right]-L,
$$

this is strictly positive (by (1)).

Now consider the incumbent. If he elicits the agent's effort then the maximum expected payoff he gets equals the expected value of the firm's terminal value, i.e. $q\left[p V^{c}-(1-p) \bar{V}\right]$, minus the expected cost of eliciting the agent's effort. Consider an optimum incentive scheme, this minimizes the Principal's (incumbent's) cost subject to the constraint that the agent exerts effort.

Lemma 2 Under no-information exchange, the optimum incentive scheme costs the incumbent $c$.

Proof. See the Appendix.

Under no-information exchange, the efficient-incentive-compatible reward scheme satisfies the agent's participation constraint at equality. The expected payoff to the incumbent conditional upon eliciting the agent's effort then equals $p\left[q V^{c}-(1-q) \bar{V}\right]-c$; this is strictly positive (by (2)). If the incumbent does not elicit the agent's effort, then his research activity fails for sure and he cannot enter the development stage, i.e. his payoff is nil. It then follows that, given the entrant resorting to $\mathrm{VC}$ financing, the incumbent finds it optimal to elicit the agent's effort. We then have that, under VC financing, the incumbent's expected payoff is $\pi_{I}^{V C}$ :

$$
\pi_{I}^{V C}=p\left[q V^{c}-(1-q) \bar{V}\right]-c
$$

and that of the entrant is $\pi_{E}^{V C}$ as given by (5).

It follows from (5) and (6) that the entrant's and the incumbent's payoff under VC financing are identical to the payoffs they would earn in the firstbest world by not agreeing to information exchange (by comparison with $\pi_{E}^{N E *}$ and $\pi_{I}^{N E *}$ ). Under VC financing, the social surplus (the sum of the entrant's and incumbent's net present value ventures, or equivalently, the sum of the entrant's and incumbent's expected payoffs) is then $S S^{V C}$ : 
$S S^{V C} \equiv \pi_{E}^{V C}+\pi_{I}^{V C}=\left\{q\left[p V^{c}+(1-p) \bar{V}\right]-L\right\}+\left\{p\left[q V^{c}+(1-q) \bar{V}\right]-c\right\}$

identical to $S S^{N E *}$ - the no-information exchange first-best social surplus .

\subsection{Incumbent's financing cum information exchange and equilibrium financing mode}

The previous section has established that VC financing is viable and that VC replicates the payoffs the parties would attain in the first-best world under no-information exchange. The issue to be addressed is whether incumbent's financing cum information exchange (IE) can dominate VC financing, and more generally be the equilibrium financing mode.

Suppose the equilibrium financing mode is IE, and let $\pi_{E}^{I E}, \pi_{I}^{I E}$ denote the entrant's and the incumbent's expected payoffs in such an equilibrium. Necessarily $\pi_{E}^{I E}, \pi_{I}^{I E}$ satisfy:

$$
\begin{aligned}
& \pi_{E}^{I E} \geq \pi_{E}^{V C}, \\
& \pi_{I}^{I E} \geq \pi_{I}^{V C} .
\end{aligned}
$$

That is, if IE is an equilibrium financing mode, then necessarily: i) it satisfies inequality (8), i.e. it provides the entrant with an expected payoff which does not fall below what he would earn under VC financing; and ii) it satisfies inequality (9). That is, IE gives the incumbent an expected payoff, $\pi_{I}^{I E}$, which is not lower than what the incumbent would obtain by not agreeing on IE, in which case the entrant would raise $\mathrm{VC}$ financing and the incumbent would earn $\pi_{I}^{V C}$.

We shall refer to (8) as to the entrant's participation constraint, and to (9) as to the incumbent's participation constraint; the constraints that must necessarily be satisfied for IE to be the equilibrium financing mode. Clearly, if (8)-(9) hold, then necessarily:

$$
S S^{I E} \equiv \pi_{I}^{I E}+\pi_{E}^{I E} \geq S S^{V C} \equiv \pi_{E}^{V C}+\pi_{I}^{V C}
$$

where $S S^{I E}$ denotes the social surplus, the sum of the entrant's and incumbent's expected payoffs (or equivalently, the sum of the entrant's and 
incumbent's net-present value ventures), which is attained under IE (incumbent financing cum information exchange); $S S^{V C}$ is the social surplus attained under $\mathrm{VC}$ financing as given by (7).

Suppose that under IE the incumbent does not elicit the agent's effort, then $S S^{I E}$ equals the sum of the entrant's and incumbents' net-present value ventures conditional upon information exchange and no-effort elicitation, i.e.

$$
S S^{I E} \equiv S S_{a=0}^{I E}=\left\{q V^{c}-L\right\}+q V^{c},
$$

and the necessary condition (10) fails to hold:

$$
S S_{a=0}^{I E}<S S^{V C} \quad(\text { by }(3)) .
$$

That is, because of (3), VC financing Pareto dominates an IE such that the incumbent does not elicit the agent's effort (incumbent's research fails for sure). ${ }^{1}$

Lemma 3 If the equilibrium financing mode is IE, then necessarily IE provides the incumbent with the incentive to elicit the agent's effort.

Proof. By contradiction. If under IE the incumbent does not elicit the agent's effort, then condition (10) fails to hold (by (3)), and IE cannot possibly satisfy the parties' participation constraints (8)-(9).

This establishes that for IE to be the equilibrium financing mode it must necessarily be that the incumbent finds it optimal to elicit the agent's effort, despite the information exchange agreement embedded in IE. That is, it must be that the incumbent's expected payoff by eliciting the agent's effort and thus entering the development stage with probability $1-(1-p)(1-q)$, does not fall below what he would get by free riding on the entrant's research activity, i.e. the payoff he would get by not eliciting the agent's effort and still entering the development stage with probability $q$, the probability that the entrant's research activity succeeds (and transferred to him thanks to the information-exchange agreement).

Let $(\alpha, S)$, where $S \geq L$, and $\alpha \leq 1$, denote an IE contract. The contract whereby the incumbent gives the entrant, at the initial date, the

\footnotetext{
${ }^{1}$ If parameter values were such to violate inequality (3), if $c$ were higher than $\bar{c}$, then information-exchange agreements that do not lead to effort elicitation (the incumbent's reasearch fails for sure) would Pareto dominate VC (no-information exchange): information exchange would always be part of an equilibrium.
} 
amount $S$ not lower than $L$ in exchange for the share $\alpha \leq 1$ of the entrant's revenue realization at the terminal date, and the parties agree to information exchange. The incumbent's expected payoff by not eliciting the agent's effort is $\pi_{I}^{I E}(a=0)$ :

$$
\pi_{I}^{I E}(a=0)=q V^{c}(1+\alpha)-S,
$$

indeed under information exchange, with no-effort elicitation both the entrant and the incumbent will enter the development stage with probability $q$, the probability that the entrant's research succeeds, and the expected revenue of each venture, conditional upon both the entrant and the incumbent entering the development stage, is $V^{c}$. Conditionally upon the entrant's research succeeding, the incumbent will then expect to earn $V^{c}$ from his venture and $\alpha V^{c}$ from his stake in the entrant's venture. His expected payoff by not eliciting the agent's effort is then $q V^{c}(1+\alpha)$ minus the transfer payment $S$ to the entrant.

If the incumbent elicits the agent's effort, then the probability of earning $V^{c}(1+\alpha)$ raises from $q$ to $[1-(1-p)(1-q)]$, but he incurs the cost of offering the agent an incentive-compatible contract. Lemma 4 below gives the cost of the optimum incentive scheme, i.e. the agent's reward scheme which minimizes the incumbent's cost subject to the constraint that the agent finds it incentive compatible to exert effort.

Lemma 4 Under information exchange, the optimum incentive scheme costs the incumbent $c+\Delta, \Delta \equiv\left[\frac{q}{p(1-q)}\right] c$.

Proof. See the Appendix.

$\Delta$ is the extra reward to be given to the agent in order for him to prefer "effort" to "shirking" (free riding on the entrant's research). The key is in that the agent can be induced to exert effort by rewarding him when the firm's terminal value is $V$, because incentive schemes cannot be conditioned on actions but rather on revenue realizations, i.e. either $V$ or 0 . Under information exchange, the agent's expected payoff by shirking is strictly positive, it amounts to $\Delta$. Indeed, even though the incumbent's research fails for sure, the firm can still enter the development stage (attain $V$ with probability $P(1-P)$ ) whenever the entrant's research succeeds. An incentive compatible contract then pays the agent the rent $\Delta$. Not surprisingly, the higher $q$ - the probability that the entrant's research succeeds - the higher the extra reward $\Delta$. 
The incumbent's expected payoff by eliciting the agent's effort is then $\pi_{I}^{I E}(a=p)$ :

$$
\pi_{I}^{I E}(a=p)=[1-(1-p)(1-q)] V^{c}(1+\alpha)-[c+\Delta]-S
$$

The incumbent finds it optimal to elicit effort if and only if:

$$
\pi_{I}^{I E}(a=p) \geq \pi_{I}^{I E}(a=0)
$$

Inequality (14) is the incumbent's incentive constraint, the constraint that must be met in order for the incumbent to elicit the agent's effort under IE. Using (12)-(13), the incentive constraint (14) can be written as:

$$
[1-(1-p)(1-q)] V^{c}(1+\alpha)-[c+\Delta] \geq q V^{c}(1+\alpha) .
$$

Lemma 5 Under information exchange, the incumbent finds it optimal to elicit the agent's effort if and only if the share of the entrant's revenue accruing to him satisfies:

$$
\begin{gathered}
\alpha \geq \alpha_{I C} \\
\alpha_{I C} \equiv \frac{c+\Delta}{p(1-q) V^{c}}-1
\end{gathered}
$$

Proof. Under information exchange, the incumbent finds it optimal to elicit the agent's effort if and only if inequality (14.a) holds. (14.a) holds iff $\alpha \geq \alpha_{I C}$.

Let $\alpha_{I C}>0$, then a corollary of Lemma 5 is that profit sharing is a necessary element of an information exchange agreement.

Conditionally upon the incumbent finding it optimal to elicit the agent's effort under information exchange, i.e. conditionally upon $\alpha \geq \alpha_{I C}$ (by Lemma 5), the entrant's and the incumbent's expected payoff under IE are respectively $\pi_{E}^{I E}(a=p), \pi_{I}^{I E}(a=p)$ :

$$
\begin{gathered}
\pi_{E}^{I E}(a=p)=[1-(1-p)(1-q)] V^{c}(1-\alpha)+(S-L), \\
\pi_{I}^{I E}(a=p)=[1-(1-p)(1-q)] V^{c}(1+\alpha)-[c+\Delta]-S .
\end{gathered}
$$


where in $(15),(S-L)$ is the transfer payment net of the cash outlay required by the entrant's project; $(S-L)$ accrues to the entrant.

Lemma 6 IE is the equilibrium financing mode if and only if there exists an $(\alpha, S)$ that satisfies the entrant's and the incumbent's participation constraints (8)-(9), the incumbent's incentive constraint (14.b) and the feasibility constraints $\alpha \leq 1, S \geq L$; that is iff:

$$
\begin{gathered}
\pi_{E}^{I E}(a=p) \geq \pi_{E}^{V C} \\
\pi_{I}^{I E}(a=p) \geq \pi_{I}^{V C} \\
1 \geq \alpha \geq \alpha_{I C} \\
S \geq L
\end{gathered}
$$

Proof. Necessity follows by Lemmas 3 and 5, and because if IE is an equilibrium, then necessarily it makes both the entrant and the incumbent better off with respect to VC (it satisfies participation constraints (8.a)(9.a)). Sufficiency: suppose that parameter values are such that $(\alpha, S)$ that satisfy (8.a)-(9.a), (17) and (18) do exist. Then IE arrangements that make both parties better off with respect to VC, i.e. Pareto improving IEs, do exist. Because this is common knowledge (information is symmetric), there will be a Pareto improving IE the parties agree upon.

Clearly if participation constraints (8.a)-(9.a) hold, then necessarily:

$$
\pi_{E}^{I E}(a=p)+\pi_{I}^{I E}(a=p) \geq \pi_{E}^{V C}+\pi_{I}^{V C},
$$

The right-hand side is the social surplus attained under $\mathrm{VC}$; that is, $\pi_{E}^{V C}+\pi_{I}^{V C} \equiv S S^{V C}$ as given by (7). This is identical to the no-information exchange first-best level $S S^{N E *}$. The left-hand side is the social surplus attained under an IE arrangement that leads to effort elicitation by the incumbent. Let it be named $S S_{a=p}^{I E}$; by using (15), (16), $S S_{a=p}^{I E}$ :

$$
S S_{a=p}^{I E} \equiv \pi_{E}^{I E}(a=p)+\pi_{I}^{I E}(a=p)=2[1-(1-p)(1-q)] V^{c}-[c+\Delta]-L
$$


$S S_{a=p}^{I E}$ equals the social surplus that would be attained in the first best world under information exchange, i.e. $S S^{E *}$, minus the "extra reward" $\Delta$ to be given to the agent for him to exert effort:

$$
S S_{a=p}^{I E}=S S^{E *}-\Delta .
$$

Inequality (19) can then be written as:

$$
S S^{E *}-S S^{N E *} \geq \Delta
$$

or equivalently:

$$
[q(1-p)+p(1-q)]\left[2 V^{c}-\bar{V}\right] \geq \Delta .
$$

The left-hand side is the ex-ante gain generated by information exchange in the First Best world; this is positive iff the development stage is sufficiently risky, that is iff $P \leq \frac{1}{2}$ (by Lemma 1 ). $\Delta \equiv\left[\frac{q}{p(1-q)}\right] c$ is the agency cost of eliciting effort under information exchange in a Second Best environment of non contractibility of actions.

Lemma 7 An $(\alpha, S)$ that satisfies the conditions at Lemma 6, i.e. inequalities (8.a),(9.a), (17) and (18), exists if and only if inequality (19.b) holds.

Proof. Necessity: if inequality (19.b) fails to hold, then participation constraints (8.a)-(9.a) cannot possibly hold. Sufficiency: if inequality (19.b) holds, then simple calculations show that: i) $\alpha_{I C}<1$, that is the incumbent's incentive constraint $\alpha \geq \alpha_{I C}$ does not violate the feasibility constraint $\alpha \leq 1$; and ii) there always exist $\alpha$ and $S$, where $1 \geq \alpha \geq \alpha_{I C}$ and $S \geq L$, that satisfy (8.a)-(9.a), or equivalently:

$$
\begin{gathered}
{[1-(1-p)(1-q)] V^{c}(1-\alpha)+S \geq q\left[p V^{c}-(1-p) \bar{V}\right],} \\
{[1-(1-p)(1-q)] V^{c}(1+\alpha)-\Delta-S \geq p\left[q V^{c}-(1-q) \bar{V}\right] .}
\end{gathered}
$$

The key to Lemma 7 is in that $S$ can exceed $L$ (by (18)) and this implies that the incumbent's incentive constraint $\alpha \geq \alpha_{I C}$ does not bite, that is the 
only constraints that bite are the parties' participation constraints (8.a)(9.a). Indeed, one can always increase $\alpha$ (satisfy the incentive constraint $\left.\alpha \geq \alpha_{I C}\right)$ and still keep parties' payoffs unchanged by increasing $S$, the transfer payment from the incumbent to the entrant, so as to offset the entrant's (incumbent's) loss (gain) that results from the increase in $\alpha .^{2}$

It then follows by Lemma 6 and Lemma 7 that IE is the equilibrium financing mode if and only if inequality (19.b) holds. Indeed, provided that condition (19.b) holds IE arrangements that satisfy the conditions at Lemma 6 do exist (by Lemma 7), and hence IEs that make both parties better off with respect to VC, i.e. Pareto improving IEs, do exist (by Lemma 6). Because this is common knowledge (information is symmetric), there will be a Pareto improving IE the parties agree upon.

Using $V^{c} \equiv P(1-P) V$, and $\bar{V} \equiv P V$, condition (19.b) can be rewritten as:

$$
V[q(1-p)+p(1-q)]\left(P-2 P^{2}\right)-\Delta \geq 0
$$

which holds for $P$ that satisfies:

$$
\begin{gathered}
\underline{P} \leq P \leq \bar{P} \\
\bar{P} \equiv \frac{\Omega+\left(\Omega^{2}-8 \Omega \Delta\right)^{\frac{1}{2}}}{4 \Omega} \\
\underline{P} \equiv \frac{\Omega-\left(\Omega^{2}-8 \Omega \Delta\right)^{\frac{1}{2}}}{4 \Omega} \\
\Omega \equiv V[q(1-p)+p(1-q)]
\end{gathered}
$$

This leads to:

Proposition 1 When $P \in[\underline{P}, \bar{P}]$, financing is provided by the incumbent and the parties agree to information exchange. When $P \notin[\underline{P}, \bar{P}]$, financing is provided by Venture Capitalist and the parties do not cooperate.

\footnotetext{
${ }^{2}$ If $S$ were constrained to be equal to $L$, then condition (19.b) would be necessary but no more sufficient.
} 
For $P \in[\underline{P}, \bar{P}]$, the ex-ante gain generated by information exchange in the First-Best world exceeds $\Delta \equiv\left[\frac{q}{p(1-q)}\right] c$, the agency cost of eliciting effort under information exchange in a Second Best environment of non contractibility of actions: The equilibrium financing mode is IE. Both $\bar{P}$ and $\underline{P}$ depend on $\Delta$, and

$$
\begin{gathered}
\Delta=0: \bar{P}=\frac{1}{2}, \underline{P}=0 \\
\forall \Delta>0: \quad 0<\underline{P}<\bar{P}<\frac{1}{2},
\end{gathered}
$$

that is were agency problems absent, like for example in family firms where the principal and the agent coexist in the same entity, then $P \leq \frac{1}{2}$ would be necessary and sufficient for ex-ante optimality of information exchange. With agency problems, the set of parameter values such that information exchange is attained shrinks. Information exchange is attained if the development stage is risky, but not "too" risky, i.e. iff $P \in[\underline{P}, \bar{P}]$. Indeed, if $P$ is sufficiently low so as to satisfy $P<\underline{P}$, then the expected value of the venture under information exchange, $V^{c}=P(1-P)$, is "too" low to make it worthwhile to incur the incremental cost $\Delta$ which is required for eliciting the agent's effort under information exchange.

When $P \in[\underline{P}, \bar{P}]$, the equilibrium financing mode is an IE. The IE, that is the $(\alpha, S)$, the parties agree upon will be the result of bargaining under symmetric information, where in the no-agreement point the parties' payoffs are the payoffs that would be attained under VC. ${ }^{3}$ Such IE is characterized in the Appendix (Equilibrium (full-financing) IE).

Few observations are in order. Strictly speaking, for $P$ that lays outside the interval $[\underline{P}, \bar{P}], \mathrm{VC}$ dominates IE. Proposition 1 states something stronger, i.e. that $\mathrm{VC}$ is the equilibrium financing mode. This is true if in this range, no arrangement can dominate $\mathrm{VC}$. This is clearly the case: for $P$ $\notin[\underline{P}, \bar{P}]$, arrangements that involve information sharing are dominated by VC, because of (3) and because (19) fails to hold. That is, because the social surplus, the sum of the entrant's and incumbent's net-present value ventures (or equivalently, the sum of the entrant's and incumbent's expected payoffs), which is attained under information exchange is lower than that attained

\footnotetext{
${ }^{3}$ Indeed, if either party refuses to agree on IE, the entrant's optimal strategy is still to undertake the project and hence to raise financing from a venture capitalist.
} 
under no-information exchange. Then in this range, the relevant alternative to VC financing is incumbent's financing with no-information exchange. This cannot dominate $\mathrm{VC}$ and is strictly inferior if the financial relationship between the incumbent and the entrant gives raise to information spillover. For $P \in[\underline{P}, \bar{P}]$, an equilibrium financing arrangement is necessarily one where the parties agree to information exchange and the incumbent holds a stake in the entrant's venture sufficiently large so as to satisfy the incentive constraint $\alpha \geq \alpha_{I C}$ (because (19) holds). For $P \in[\underline{P}, \bar{P}]$, an equilibrium (full-financing) IE, an $(\alpha, S)$ with $S \geq L$, always exists and is characterized in the Appendix. However, if the entrant's financing need, $L$, is sufficiently large, then there exists a payoff-equivalent (partial-financing) IE where the incumbent provides part of the financing, $S<L$, in exchange for a share $\alpha \geq \alpha_{I C}$ and the remaining $L-S$ is provided by a venture capitalist (see the Appendix). That is for $P \in[\underline{P}, \bar{P}]$, if $L$ is sufficiently large then incumbent financing cum information exchange can coexist with $\mathrm{VC}$ financing. However this coexistence result is specific to the binary actions' model, with a continuum of actions it does not survive.

\section{Continuum of actions}

We have characterized the solution under the simplifying assumption that the agent has a binary actions' choice, $a \in\{0, p\}$. We illustrate below the implications that result from a continuum of actions. The main point to be made is that the (possible) coexistence of incumbent's financing and VC financing does not survive.

Suppose that the agent chooses the probability of success of the research stage, $p$, within the unit interval, that is

$$
p \in[0,1]
$$

The agent's cost of effort/probability $p$ is $c(p)$ continuously differentiable, non-negative, increasing and convex: $\forall p \in(0,1], c(p) \geq 0, c^{\prime}(p)>0, c^{\prime \prime}(p)>$ 0 . Moreover, $c(0)=0, c^{\prime}(0)=0, \lim _{p \longrightarrow 1} c(p)=\infty$.

Lemma 8 The minimum cost of eliciting effort level $p$ under information exchange, $C(p \mid E)$, equals the minimum cost of eliciting $p$ under no-information exchange, $C(p \mid N E)$, plus the agent's rent $\Delta(p)$ increasing 
in $p$ :

$$
\begin{gathered}
C(p \mid E)=C(p \mid N E)+\Delta(p) \\
C(p \mid N E) \equiv p c^{\prime}(p) \\
\Delta(p) \equiv \frac{q}{1-q} c^{\prime}(p)
\end{gathered}
$$

Proof. See the Appendix.

Suppose that the parties have agreed to exchange information and that the incumbent is entitled to the share $\alpha$ of the entrant's revenue, then the incumbent will offer the agent the incentive scheme that elicits effort level $p^{E}(\alpha)$ :

$$
p^{E}(\alpha)=\underset{p}{\arg \max }\left\{[1-(1-q)(1-p)] V^{c}(1+\alpha)-C(p \mid E)\right\}
$$

$p^{E}(\alpha)$ satisfies the first-order condition:

$$
(1-q) V^{c}(1+\alpha)=\frac{\partial C(p \mid E)}{\partial p}
$$

the left-hand side of (25) is the incumbent's marginal benefit of effort; the right hand side is the marginal cost of effort, and it is increasing in $p$ (because $C(p \mid E)$ is convex in $p)$. Hence, $p^{E}(\alpha)$ is increasing in $\alpha$ : the higher the share of the entrant's revenue that accrues to the incumbent, $\alpha$, the higher the benefits to the incumbent of eliciting effort, the higher the effort level he finds it optimal to elicit and hence the higher the social gains from cooperation.

Let $S S^{E}(\alpha)$ denote the social surplus generated under information exchange, when a share $0 \leq \alpha \leq 1$ of the entrant's revenue accrues to the incumbent. This is given by:

$$
S S^{E}(\alpha)=\left[1-(1-q)\left(1-p^{E}(\alpha)\right)\right] 2 V^{c}-C\left(p^{E}(\alpha) \mid E\right)-L
$$

Lemma $9 S S^{E}(\alpha)$ is monotonically increasing in $\alpha$.

Proof. Because $p^{E}(\alpha)$ is the solution to (24), and $\alpha \leq 1$.

It follows by Lemma 9 that the gains from information exchange are maximized by maximizing the share of the entrant's venture accruing to the incumbent. This amounts to minimizing the share accruing to outside financiers, and hence to having the incumbent being the only funds' provider. Since the equilibrium financing mode is necessarily that which maximizes 
the social surplus (by the same reasoning as in Section 3), we immediately have:

Lemma 10 If information exchange is part of an equilibrium, then financing is provided entirely by the incumbent.

With a continuum of actions, the coexistence of $\mathrm{VC}$ financing and incumbent's financing cannot be an equilibrium. The equilibrium financing mode is either VC financing or incumbent's financing cum information exchange. The latter occurs iff the ex-ante gains from information exchange exceed agency costs (by the same reasoning as in Section 3). If this is the case then the equilibrium financing mode is full-financing IE, that is an $(\alpha, S)$ with $S \geq L$. The IE the parties agree upon is that which results from bargaining along the lines illustrated in the Appendix for the derivation of the full-financing IE in the binary actions' model.

\section{$5 \quad$ Patentability and Licensing}

Suppose the research output is patentable. Then licensing will allow the parties to share the research result ex post, since the innovator (licensor) can give its rival (licensee) the right to use the innovation in exchange for a fee. Suppose that the parties have not engaged in information exchange and that one of them is successful at the research stage, then the status quo will be one where the expected payoff of the successful firm (licensor) is $\bar{V}$ and that of its rival (licensee) is nil. If the innovation is licensed, then each of the two firms will earn $V^{c}$ in expected value. Therefore, licensing is efficient if:

$$
2 V^{c} \geq \bar{V}
$$

or equivalently if:

$$
P \leq \frac{1}{2}
$$

which is exactly the same condition required for information exchange being optimal in a First-Best world (Lemma 1).

Licensing is a perfect substitute for information exchange: it allows both firms to use the research result in the product-development stage, exactly as with information exchange. Moreover, because the agent's reward can be conditioned on the patent being attained, the minimum expected 
cost of eliciting effort $p$ under licensing, $C(p \mid L)$, is exactly the same as that under no-information exchange, i.e. $C(p \mid L) \equiv C(p \mid N E)$, whereas the minimum expected cost of eliciting effort $p$ under information exchange is $C(p \mid E)>C(p \mid N E) \equiv C(p \mid L)$ (by Lemma 8), because under information exchange, the agent can free ride on the rival's research activity. Thus, if the research output is patentable, the total surplus generated under noinformation exchange cum efficient licensing exceeds that attained under information exchange. Since the equilibrium financing mode is necessarily that which maximizes the social surplus, we have:

Proposition 2 If the research output is patentable, then information exchange is implemented ex-post via licensing and the equilibrium financing mode is Venture Capital financing.

\section{Conclusion}

Venture financing is provided not only by purely financial investors, but also by corporations whose business is related with those of the new ventures being financed. Does the identity of the investor matter, and what drives the choice of the financing mode? The answer provided by this paper is that corporate financing cements cooperation between the corporation and the start-up. The choice of the investor is then a by-product of the choice about whether to cooperate or not. We have modelled cooperation as sharing research results (information exchange). Even though the two firms may compete fiercely in the final product market, cooperation may still be beneficial in that it enhances the likelihood that a marketable product will be developed. However, cooperation gives raise to a double moral hazard problem. Agents involved in the research activity may wish to free ride on the rival and this implies that incentive schemes become costlier. Holding a stake in the counterpart's venture allows the incumbent to internalize part of the benefits, the greater the stake the greater the extent to which the parties cooperate in maximizing the likelihood that the overall research activity will succeed. Maximizing the gains from cooperation then requires full financing being provided by the incumbent. We then have the result that if cooperation is optimal, i.e. if the benefits attainable in a First-Best world are not undermined by the agency costs that cooperation carries, then the in- 
vestor will not be a pure financial institution but rather the company whose business is prone to synergies with the start-up. Whether cooperation is desirable, crucially depends on whether research results are patentable. If they are patentable, then licensing will allow the parties to share research results ex post, since the licensor (the innovator) can give its rival (licensee) the right to use the innovation in exchange for a fee. Licensing then allows the two parties to use research results in the product-development stage exactly as with information exchange, without incurring in the free raiding problems that information exchange gives raise. Consequently, if the research output is patentable, then the total surplus generated under no-information exchange cum efficient licensing exceeds that attained under information exchange and the equilibrium financing mode has financing provided by a pure financial institution. 


\section{References}

D'Aspremont, C., S. Bhattacharya, and L.A. Gerard-Varet (2000), "Bargaining and Sharing Innovative Knowledge", Review of Economic Studies 67, 255-272.

Bhattacharya, S., J. Glazer, and D. Sappington (1992), " Licensing and the Sharing of Knowledge in Research Joint Ventures", Journal of Economic Theory 56, 43-69.

Bhattacharya, S., and G. Chiesa (1995), " Proprietary Information, Financial Intermediation and Research Incentives", Journal of Financial Intermediation 4, 328-357.

Grossman, S., and O. Hart (1983), "An Analysis of the Principal-Agent Problem", Econometrica 51, 927-940.

Hellmann, T. (2002), "A Theory of Strategic Venture Investing" , Journal of Financial Economics 64, 285-314.

Katz, M. and C. Shapiro (1987)," R\&D Rivalry with Licensing or Imitation", American Economic Review rr, 400-420.

Severinov S. (2001), "On Information Sharing and Incentives in R\&D", Rand Journal of Economics 32, 542-564. 


\section{Appendix}

\section{Proof of Lemma 2}

Let $Z$ denote the payment from the incumbent to the agent in the event that the firm's terminal value is $V$. Then, under no-information exchange, the incumbent's minimum expected cost of eliciting the agent's effort is the solution of the following problem:

$$
\begin{gathered}
\min _{Z}\{p[q P(1-P)+(1-q) P] Z\} \\
\text { s.t. } \\
p=\underset{a \in\{0, p\}}{\arg \max }\{a[q P(1-P)+(1-q) P] Z-c(a)\} \\
p[q P(1-P)+(1-q) P] Z-c \geq 0
\end{gathered}
$$

$(A .1 a)$ is the agent's incentive constraint, $(A .1 b)$ is the agent's participation constraint conditionally upon action $a=p$. At the optimum, (A.1a) binds:

$$
p[q P(1-P)+(1-q) P] Z-c=0
$$

and this implies that the agent's expected payoff equals his reservation utility. Let $Z^{*}$ denote the solution to the minimization-cost problem $(A .1)$. The incumbent's cost of eliciting the agent's effort is $c$ :

$$
p[q P(1-P)+(1-q) P] Z^{*}=c \quad(\text { by }(\text { A.2 })) .
$$

\section{Lemma 2 is proved}

\section{Proof of Lemma 4}

Under information exchange, the incumbent's minimum expected cost of eliciting the agent's effort is the solution of the following problem:

$$
\begin{gathered}
\min _{Z}\{[1-(1-p)(1-q)] P(1-P) Z\} \\
\text { s.t. } \\
p=\underset{a \in\{0, p\}}{\arg \max }\{[1-(1-a)(1-q)] P(1-P) Z-c(a)\}
\end{gathered}
$$




$$
[1-(1-p)(1-q)] P(1-P) Z-c \geq 0
$$

where $Z$ is the payment from the incumbent to the agent in the event that the firm's terminal value is $V$. $(A .3 b)$ is the agent's participation constraint conditionally upon action $a=p .(A .3 a)$ is the agent's incentive constraint, this can be written as:

$$
[1-(1-p)(1-q)] P(1-P) Z-c \geq q P(1-P) Z
$$

The right-hand side of $(A .3 c)$ gives the agent's expected payoff by exercising no effort (i.e. $a=0$ ), in which case his expected payoff is strictly positive, i.e. it is $P(1-P) Z$, whenever the entrant's research is successful, this occurs with probability $q$. The left-hand side of $(A .3 c)$ gives the agent's expected payoff by exercising effort (i.e. $a=p$ ); by exercising effort the probability according to which his expected payoff attains the strictly-positive value $P(1-P) Z$ raises from $q$ to $[1-(1-p)(1-q)] \equiv q+(1-q) p$, but he suffers the cost $c$.

At the optimum, the incentive constraint is binding, but since by exercising no effort the agent free rides on the entrant's result, his expected payoff exceeds his reservation utility (the participation constraint is slack). The solution to the minimization-cost problem $(A .3)$ is $Z^{*}$ :

$$
Z^{*}=\frac{c}{p(1-q)[P(1-P)]}
$$

The expected cost of eliciting the agent's effort, is thus:

$$
[1-(1-p)(1-q)] P(1-P) Z^{*} \equiv c+\left[\frac{q}{p(1-q)}\right] c .
$$

\section{Lemma 4 is proved}

\section{Equilibrium (full-financing) IE}

Let condition (19.b) hold, or equivalently $P \in[\underline{P}, \bar{P}]$. Then because the social surplus (the sum of the incumbent's and entrant's expected payoffs) attained under IE exceeds that attained under $\mathrm{VC}, S S_{a=p}^{I E}>S S^{V C}$, there is scope for the parties to reach an IE agreement that makes both of them better off with respect to VC. Let $\mu$ be the entrant's bargaining power, 
the incumbent's bargaining power is $(1-\mu)$. By standard arguments, in the equilibrium of the bargaining game, the entrant's and the incumbent's payoffs are $\pi_{E}^{I E}(a=p), \pi_{I}^{I E}(a=p)$ :

$$
\begin{gathered}
\pi_{E}^{I E}(a=p) \equiv \pi_{E}^{V C}+\mu\left[S S_{a=p}^{I E}-S S^{V C}\right] \\
\pi_{I}^{I E}(a=p) \equiv \pi_{I}^{V C}+(1-\mu)\left[S S_{a=p}^{I E}-S S^{V C}\right]
\end{gathered}
$$

where $\pi_{E}^{V C}, \pi_{I}^{V C}$ are respectively the entrant's and the incumbent's payoffs in the no-agreement point (VC financing); $S S_{a=p}^{I E}$ is the social surplus attained under an IE such that the incumbent elicits the agent's effort, $S S_{a=p}^{I E}$ is given by $(20)$ :

$S S_{a=p}^{I E} \equiv \pi_{E}^{I E}(a=p)+\pi_{I}^{I E}(a=p)=2[1-(1-p)(1-q)] V^{c}-[c+\Delta]-L ;$

$S S^{V C}$ is the social surplus attained under $\mathrm{VC}$, that is

$$
S S^{V C} \equiv \pi_{E}^{V C}+\pi_{I}^{V C}
$$

as given by (7); the expression $\left[S S_{a=p}^{I E}-S S^{V C}\right] \equiv\left[\left(S S^{E *}-\Delta\right)-S S^{N E *}\right]$ is then the gain generated by agreeing to an IE that provides the incumbent with the incentive to elicit the agent's effort. This gain is positive under our maintained hypothesis that (19.b) holds. The IE the parties agree upon is $(\alpha, S)$ such that parties' payoffs are $\pi_{E}^{I E}(a=p), \pi_{I}^{I E}(a=p)$ as given by (A.4), (A.5), and therefore it is $(\alpha, S)$ that solves:

$$
\begin{gathered}
{[1-(1-p)(1-q)] V^{c}(1-\alpha)+(S-L)=\pi_{E}^{V C}+\mu\left[S S_{a=p}^{I E}-S S^{V C}\right]} \\
{[1-(1-p)(1-q)] V^{c}(1+\alpha)-[c+\Delta]-S=\pi_{I}^{V C}+(1-\mu)\left[S S_{a=p}^{I E}-S S^{V C}\right]} \\
1 \geq \alpha \geq \alpha_{I C} \\
S \geq L
\end{gathered}
$$


where the left-hand side of (A.6) is the payoff the entrant gets under $(\alpha, S)$, the left-hand side of (A.7) is the incumbent's payoff under $(\alpha, S)$, conditionally upon the incumbent eliciting the agent's effort (i.e. conditionally upon $\alpha \geq \alpha_{I C}$ ). The right-hand side of (A.6) and that of (A.7) are, respectively, the entrant's and the incumbent's payoffs in the equilibrium of the bargaining game, that is $\pi_{E}^{I E}(a=p), \pi_{I}^{I E}(a=p)$ as given by (A.4), (A.5). An $(\alpha, S)$ that satisfies (A.6)-(A.9) thus provides the parties with the payoffs defined by the equilibrium of the bargaining game. Condition (19.b) being satisfied implies that $\alpha_{I C}<1$, moreover $S$ can exceed $L$. Then, simple calculations show that there exist $(\alpha, S)$, with $1 \geq \alpha \geq \alpha_{I C}$ and $S \geq L$, that solve (A.6)-(A.7). That is, the set of feasible $(\alpha, S)$ that provide the entrant with a payoff identical to $\pi_{E}^{I E}(a=p)$ as given by (A.4) and the incumbent with a payoff identical to $\pi_{I}^{I E}(a=p)$ as given by (A.5), is non empty. The IE the parties agree upon, will be an $(\alpha, S)$ that belongs to this set.

\section{Payoff-equivalent partial-financing IE - Coexistence of incum- bent financing and VC financing.}

Consider a partial-financing IE, an $(\alpha, S)$ with $S<L$. Under this arrangement, the incumbent finances the entrant's venture up the amount $S<L$, in return for a share $\alpha \leq 1$ of the entrant's revenue realization at the terminal date and the parties agree to information exchange. The entrant raises the remaining amount, $L-S$, from a competitive venture capital.

Lemma A.1 Let condition (19.b) hold, or equivalently $P \in[\underline{P}, \bar{P}]$, and let $L$ be sufficiently large so as to satisfy:

$$
L>[1-(1-p)(1-q)] V^{c}\left(1+\alpha_{I C}\right)-[c+\Delta]-\pi_{I}^{I E}(a=p),
$$

where $\pi_{I}^{I E}(a=p)$ is defined by (A.5). Then there exists a partial-financing IE which is payoff equivalent to equilibrium (full-financing) IE.

\section{Proof:}

A partial-financing IE, an $(\alpha, S)$ with $S<L$, is payoff equivalent to equilibrium (full-financing) IE, if and only if $(\alpha, S)$ satisfies:

$$
\begin{gathered}
{[1-(1-p)(1-q)] V^{c}(1-\alpha)-(L-S)=\pi_{E}^{I E}(a=p)} \\
{[1-(1-p)(1-q)] V^{c}(1+\alpha)-(c+\Delta)-S=\pi_{I}^{I E}(a=p)}
\end{gathered}
$$




$$
\begin{gathered}
1 \geq \alpha \geq \alpha_{I C} \\
S<L,
\end{gathered}
$$

where, $\pi_{E}^{I E}(a=p)$ is defined by (A.4), $\pi_{I}^{I E}(a=p)$ is defined by (A.5).

The right-hand side of (A.11) and the right-hand side of (A.12) are respectively the entrant's and the incumbent's payoffs under an equilibrium (full-financing) IE. The left-hand side of (A.11) and the left-hand side of (A.12) are respectively the entrant's and the incumbent's payoffs under an $(\alpha, S)$ that sets $\alpha \geq \alpha_{I C}$ (the incumbent elicits the agent's effort) and $S<L$, that is the entrant raises the amount $L-S$ from a competitive venture capital. Clearly, an $(\alpha, S)$ that satisfies (A.11)-(A.14) is by all means payoffequivalent to an equilibrium (full-financing) IE. Proving Lemma A.1 then it amounts to proving that for $L$ that satisfies inequality (A.10), such an $(\alpha, S)$ exists.

Define $\bar{S}$ as

$$
\bar{S} \equiv[1-(1-p)(1-q)] V^{c}(1+\bar{\alpha})-(c+\Delta)-\pi_{I}^{I E}(a=p),
$$

and let:

$$
\bar{\alpha}=\alpha_{I C},
$$

then $\bar{S}$ is identical to the right-hand side of (A.10), that is:

$$
\bar{S}<L \quad(\text { by A.10) }
$$

and therefore $(\bar{\alpha}, \bar{S})$ satisfies inequalities (A.13)-(A.14). Moreover, for $\alpha=\bar{\alpha}$, and $S=\bar{S}$, the left-hand side of (A.11) is identical to the righthand side, and the same holds for (A.12). This establishes that $(\bar{\alpha}, \bar{S})$ satisfies (A.11)-(A.14), and therefore that for $L$ that satisfies inequality (A.10) there exists at least one partial-financing IE which is payoff-equivalent to an equilibrium (full-financing) IE. By the same reasoning, one also proves that for $L$ sufficiently large there exist payoff-equivalent partial-financing IEs that set $\alpha>\alpha_{I C}$. 


\section{Proof of Lemma 8}

The minimum cost of eliciting $p$ under no-information exchange is $C(p \mid N E)$ :

$$
C(p \mid N E)=p[(1-q) P+q P(1-P)] Z^{*}
$$

where

$$
\begin{array}{r}
Z^{*}=\underset{Z}{\arg \min }[(1-q) P+q P(1-P)] Z \\
\text { s.t. } \\
p: \underset{p}{\arg \max }\{p[(1-q) P+q P(1-P)] Z-c(p)\} \\
p[(1-q) P+q P(1-P)] Z-c(p) \geq 0
\end{array}
$$

where $Z$ is the payment from the incumbent to the agent in the event that the firm's terminal value is $V$.

The incentive constraint $(A .15 a)$ is equivalent to the first-order condition:

$$
[(1-q) P+q P(1-P)] Z=c^{\prime}(p)
$$

and this implies that

$$
Z^{*}=\frac{c^{\prime}(p)}{[(1-q) P+q P(1-P)]}
$$

and therefore that:

$$
C(p \mid N E)=p c^{\prime}(p)
$$

The minimum cost of eliciting $p$ under information exchange is $C(p \mid E)$ :

$$
C(p \mid E)=[1-(1-q)(1-p)] P(1-P) Z^{*}
$$

where

$$
\begin{gathered}
Z^{*}=\underset{Z}{\arg \min }[1-(1-q)(1-p)] P(1-P) Z \\
\text { s.t. } \\
p: \underset{p}{\arg \max }\{[1-(1-q)(1-p)] P(1-P) Z-c(p)\} \\
{[1-(1-q)(1-p)] P(1-P) Z-c(p) \geq 0}
\end{gathered}
$$


From the first-order condition:

$$
(1-q) P(1-P) Z=c^{\prime}(p)
$$

This implies that:

$$
Z^{*}=\frac{c^{\prime}(p)}{[(1-q) P(1-P)]}
$$

and therefore that:

$$
C(p \mid E)=p c^{\prime}(p)+\frac{q}{1-q} c^{\prime}(p)
$$

or equivalently:

$$
C(p \mid E)=C(p \mid N E)+\frac{q}{1-q} c^{\prime}(p) .
$$

Lemma 8 is proved 


\section{Table 1}

Expected value of the Entrant's and Incumbent's ventures

$$
\begin{aligned}
& \text { Entrant Incumbent } \\
& E\left(\widetilde{V}_{E} \mid r_{E}=k, r_{I}=k\right)=V^{c} \quad E\left(\widetilde{V}_{I} \mid r_{E}=k, r_{I}=k\right)=V^{c} \\
& E\left(\widetilde{V}_{E} \mid r_{E}=\emptyset, r_{I}=k\right)=0 \quad E\left(\widetilde{V}_{I} \mid r_{E}=\emptyset, r_{I}=k\right)=\bar{V} \\
& E\left(\widetilde{V}_{E} \mid r_{E}=k, r_{I}=\emptyset\right)=\bar{V} \quad E\left(\widetilde{V}_{I} \mid r_{E}=k, r_{I}=\emptyset\right)=0 \\
& E\left(\widetilde{V}_{E} \mid r_{E}=\emptyset, r_{I}=\emptyset\right)=0 \quad E\left(\widetilde{V}_{I} \mid r_{E}=\emptyset, r_{I}=\emptyset\right)=0 \\
& V^{c} \equiv P(1-P) V ; \quad \bar{V} \equiv P V
\end{aligned}
$$

Figure 1: Sequence of choices and events

0

Financing mode,

Entrant invests
2

3

Payoffs are realized

Research stage:

1.a

incumbent chooses agent's incentive scheme 1.b

agent

chooses effort
$1 . c$

Research results are delivered 